\title{
Correspondance
}

\section{Nuts, omega-3s and food labels}

T $\mathrm{t}$ is misleading to suggest, as Erica 1 Weir and associates ${ }^{1}$ have done in a recent Public Health article, that nuts and seeds (other than flaxseed) are sources of omega-3 fatty acids. One hundred grams of the oil extracted from the most common nuts (peanut, coconut, almond, hazel, Brazil and cashew) would provide about $900 \mathrm{kcal}$ of energy but no omega-3 fatty acids. Of the oils from these nuts, that of cashew has the highest omega- 3 fatty acid content, at only $0.14 \mathrm{~g} / 100 \mathrm{~g}{ }^{2}$ The only nuts that are good sources of omega-3 fatty acid are walnut $(10.4 \%$ of the oil $)^{2}$ and the almost-extinct butternut.

As a practical tip for Canadians, unhydrogenated canola oil is cheap and contains about $10 \%$ omega- 3 fatty acid $(\alpha$-linoleic acid) without an excessively high content of omega- 6 fatty acid (linoleic acid). ${ }^{2}$ Similarly, flaxseed oil, at $55 \%$ omega- 3 fatty acid, may be used as a supplement. ${ }^{2}$ Any oily fish contains the longer-chain omega- 3 fatty acids eicosapentaenoic acid and docosahexaenoic acid, which lower triglycerides and have other health benefits. ${ }^{3}$

Arguably, the most successful secondary prevention trial for heart disease was the Lyon Diet Heart Study, ${ }^{4}$ in which the only intervention was a daily dose of about 2 tablespoons (about 30 $\mathrm{mL}$ ) of unhydrogenated canola oil in the form of a margarine. Omega-3 fatty acids are vitally important, and our new food labels should indeed help us to make informed choices.

\section{Eddie Vos}

Sutton, Que.

\section{References}

1. Weir E, Traynor M, Levin W. Nutrition labelling tidbits. CMA7 2004;170(10):1538-9.

2. Search the USDA National Nutrient Database for Standard Reference, release 16-1 [online]. [place unknown]: USDA Nutrient Data Laboratory; 2004. Available: www.nal.usda.gov/fnic /foodcomp/search/ (accessed 2004 Aug 17).

3. Harris WS, Connor WE, Illingworth DR, Rothrock DW, Foster DM. Effects of fish oil on VLDL triglyceride kinetics in humans. 7 Lipid Res 1990;31(9):1549-58.

4. Leaf A. Dietary prevention of coronary heart disease. The Lyon Diet Heart Study [editorial]. Circulation 1999;99:733-5.

DOI:10.1503/cmaj.1040840

\section{[One of the authors responds:]}

W e agree with Eddie Vos that the text of our article on nutrition labelling ${ }^{1}$ mistakenly suggests that omega-3 fatty acids are found in "many fish, nuts, seeds and oils." The text should have stated that omega-3 fatty acids are found in "many fish and in some nuts, seeds and oils." Table 1 in our article ${ }^{1}$ places appropriate emphasis on the major food sources of omega-3 fatty acids, as does Vos's letter.

\section{Erica Weir}

Associate Medical Officer of Health

Kingston, Frontenac and Lennox \&

Addington Health Unit

Kingston, Ont.

\section{Reference}

1. Weir E, Traynor M, Levin W. Nutrition labelling tidbits. CMA7 2004;170(10):1538-9.

DOI:10.1503/cmaj.1041251

\section{Canadian Adverse Events Study}

D oss Baker and associates, in their Kstudy of adverse events (AEs) in Canadian hospitals, ${ }^{1}$ used a method that has been used in other countries to characterize this problem, but we feel that this method underestimates the impact of adverse drug events in Canadian hospitals.

First, of the 18 predefined criteria used in stage 1 of the study, the occurrence of an adverse drug reaction was the only criterion used to screen for possible drug-related AEs. However, in the pharmaceutical care model estab- 